\title{
MODELLING METHODS - REPURPOSING A DISCRETE EVENT SIMULATION MODEL TO INCLUDE COVID 19 WORKFLOW CHANGES IN A COMPUTED TOMOGRAPHY DEPARTMENT
}

\author{
Mary Conlon \\ National University of Ireland, Galway \\ Health Service Executive \\ m.conlon17@nuigalway.ie
}

\author{
Dr. Owen Molloy \\ National University of Ireland, Galway \\ owen.molloy@nuigalway.ie
}

\author{
Ms Avril Hanly \\ Health Service Executive \\ Portiuncula University Hospital \\ avrilm.hanly@hse.ie
}

\begin{abstract}
The importance of infection control has taken centre stage with the arrival of Covid-19, and radiology staff must take precautions to limit contamination. This paper identified the changes required to an existing discrete event simulation model of a CT service to repurpose it for post COVID-19. Methods: Radiology workflow was mapped using Microsoft Visio to capture changes to roles, tasks and communications. Task and delay times were observed. Interviews with cleaning and clinical staff verified observational findings. Rich picture diagramming was used to include staff perceptions. In partnership with decision makers a culturally desirable and feasible scenario was identified and the increase in the consumed staff time post COVID-19 demonstrated. Conclusion: While CT throughput has decreased, the individual inpatient workload in terms of staff resource utilisation has increased. Separate inpatient and outpatient services are recommended to increase throughput and efficiency.
\end{abstract}

Keywords: Computed tomography, discrete event modelling, COVID-19, Rich Picture

\section{INTRODUCTION}

We are passengers on an aircraft which we endeavour to fly and redesign in mid-flight (Sterman, 2001). With crowded waiting rooms a thing of the past, COVID-19 has rendered many models of radiology service delivery obsolete. Responding to a call to arms, this empirical work examines how an existing model was repurposed with COVID-19 parameters (Currie et al., 2020).

Demand for CT is partially driven by population growth and age profile as well as increased incidences of chronic diseases (Adam, 2006; Central Statistics Office., 2015; The Royal College of Radiologists, 2020). Other factors affecting demand include increased screening and new clinical guidelines which incorporate CT in the clinical pathways. Demand for CTs has increased by $10 \%$ and demand for MRIs by 8\% over the past year (The Royal College of Radiologists, 2020).

The importance of infection control has taken centre stage with the arrival of COVID-19, and radiology staff must take precautions to limit contamination (Zanardo et al., 2020). Twenty minutes to one hour of downtime is necessary where scanners have been used for suspected or confirmed cases of the virus and where the patient requires aerosol generating procedures. The allocation of dedicated COVID-19 CT scanners in departments has been recommended but may not always be feasible in single scanner departments (Mossa-Basha et al., 2020; Orsi et al., 2020). 
In "A guide for building hospital simulation models" three simulation methods were evaluated: discrete event simulation (DES), system dynamics (SD), and agent-based simulation (Gunal, 2012). While SD considers entire cohorts and populations, the other methods consider the individual. Where SD uses rates to pass a population through its model, DES uses process blocks and the individual agents/patients moves through as a complete entity. DES models are stochastic in nature and can take account of variability in the time taken to carry out activities and the times between arrivals into the system, as well as the utilisation of resources (Currie et al., 2020). DES has been used extensively in radiology and has touched on service improvement, staff burnout and fatigue, pathway redesign (Booker et al., 2016; Oh et al., 2011; Rachuba et al., 2018; Reinus et al., 2000; Van Lent et al., 2012).

This case study elicited knowledge from radiology staff using RP diagramming, workflow analysis and observation to create a shared understanding and identified factors affecting CT service delivery during a pandemic. The intertwined elements of a CT service including the motivations and priorities of those involved in the service are examined using tools from soft systems methodology (SSM) (Crowe et al., 2017). Opportunities for service improvement were identified and tested in the resultant discrete event simulation model of the service to determine their impact on the CT waiting list and staff workload. Finally, feasible and culturally desirable targeted simulations were identified for testing in the DES model which are applicable in the context of service provision during a pandemic. This paper sets out to:

1. Provide input parameters for a simulation model of a CT service specific to the handling of COVID-19 cases.

2. Determine how staff workflow and workload in terms of consumed staff time has changed because of COVID-19.

3. Make desirable and feasible recommendations for future service delivery.

\section{METHODOLOGY}

The case study hospital provides a 24/7 acute surgical, medical and critical care service with emergency and maternity services with approximately 100 inpatient beds. In radiology, a single CT scanner provides a scheduled service from $8.30 \mathrm{am}$ to $5 \mathrm{pm}$ with a 24 -hour emergency service for inpatients and accident and emergency patients. Approval to conduct the study was obtained from the hospital management team. The researcher was employed as a radiographer for four years in the CT department prior to commencing the research work. The identity of the radiographer as a researcher and the purpose of the research were disclosed to the staff before interview. Anonymized data was used and stored in line with local data protection guidelines. A framework was developed for a simulation-based decision support system for the CT Department, Figure 1. The iterative approach taken proved capable of accommodating the changed circumstances resulting from the COVID-19 epidemic, allowing repurposing of the model.

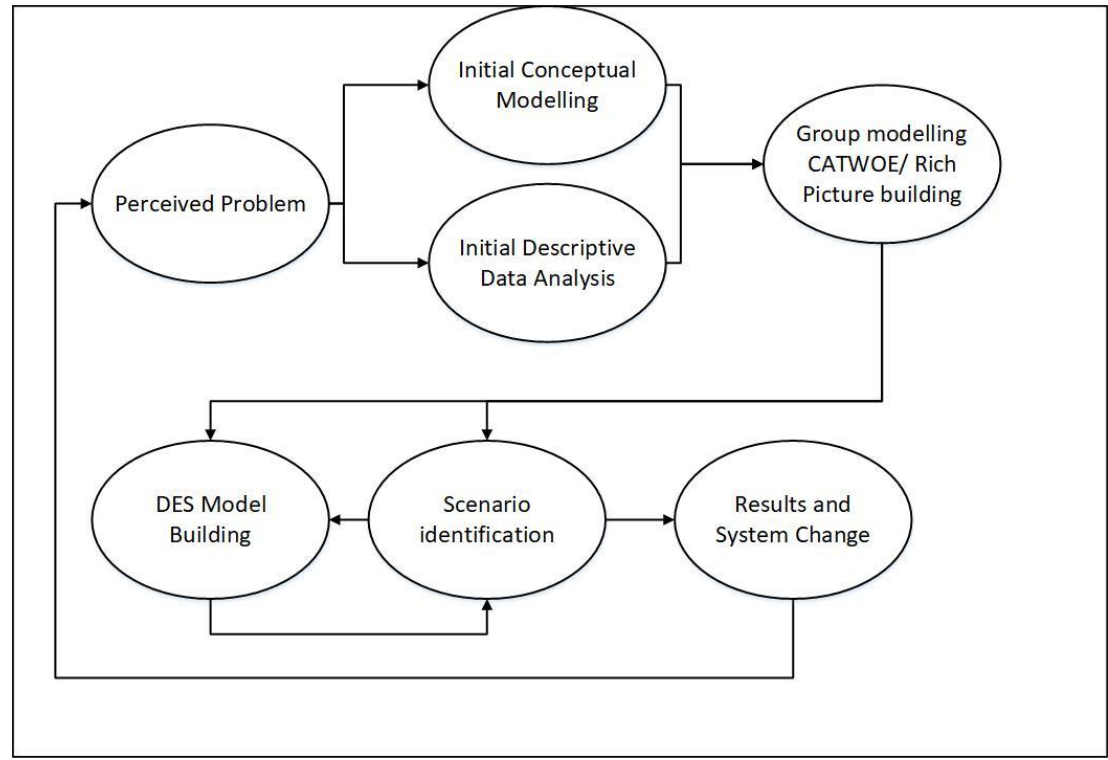

Figure 1 Framework used to create decision support tool 
Stakeholders at both clinical and managerial levels participated in model development and scenario identification. Process maps were created of the workflow when scanning a suspected or confirmed COVID-19 case and those patients undergoing procedures potentially capable of generating aerosols. CT cases where the patient undergoes aerosol generated procedures (AGP) such as high flow oxygen therapy or open airway suction result in one hour of downtime before the CT room can be cleaned (HSE, 2020). Following augmentation of an earlier RP diagram, decision makers were prompted to consider feasible and desirable service improvements in the post COVID-19 context.

An existing model of the service created using the software AnyLogic (University Edition 8.4) included delays, queues, utilisation of resources, decisions, phone call interruptions, administrative activities and the patient journey. Observed triangular stochastic delays (minimum, maximum and mode) resulting from transportation and manual handling delays were incorporated into the model with different likelihoods for the inpatient and outpatient cohorts. Likewise, Poisson arrival schedules based on historical data were created for the inpatient and outpatient (including general practitioner (GP) patient) sources. A waiting list object was created to initiate the model with a queue of existing outpatients and GP patient requests which was based on the real waiting list and categorised by exam type. A third source was created with actual arrival times for one year of patient examinations. This was used to run the model in historical mode. In this mode historical arrival times and exam types were used to compare actual patient time in CT with model patient time in CT for the purpose of model validation.

Decisions regarding preparation, number and type of staff required, patient prioritisation and workflow were captured pre and post COVID-19. Schedules were designed for each scenario. When running stochastically, patients are assigned age, infectiousness, mobility and exam type attributes based on custom distributions for each which was based on an analysis of historical data (Conlon \& Molloy, 2019). Figure 2 depicts a subsection of the DES model related to manual handling and infection control. In the figure, flexible staff are required to assist in manual handling of patients and time delays result when sourcing them. The patient is released from CT and the CT scanner is unavailable until the wrap up task which is cleaning is completed.

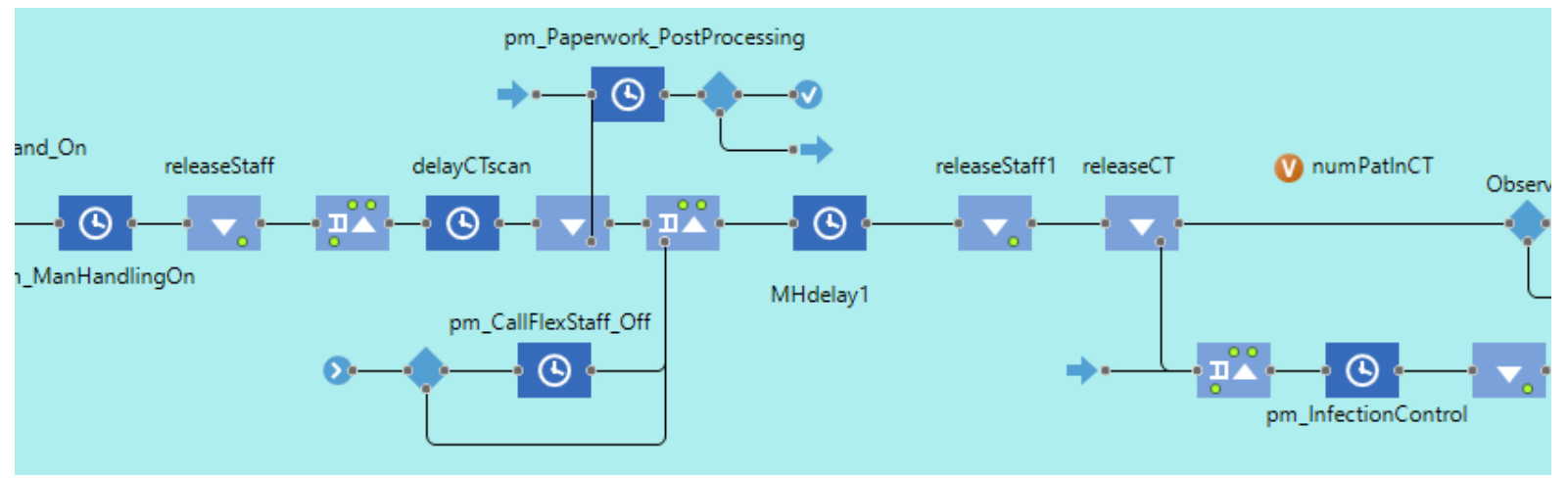

Figure 2 Subsection of DES AnyLogic model

The model included logic, animation and statistics/metrics pages. The statistics page provided a dashboard including scanner, radiographer and healthcare assistant utilization, consumption of staff time, and growth of the CT waiting list.

\subsection{Repurposing the Model for COVID-19}

The stochastic variations in time taken to scan suspected and confirmed, AGP and non AGP COVID19 cases were observed. The CT workflow for these cases was documented. Cleaning staff and the CT clinical specialist were interviewed to verify the task times and workflow observations. A custom distribution table was used to allocate a COVID-19 infection status to Inpatients. Currently COVID-19 positive outpatients are not given appointments. The stochastic arrival of outpatient's was reduced to reflect the limited service. A database was created for cleaning times for cases where the patient was:

1. Not considered infectious and standard precautions taken,

2. Confirmed or suspected as having COVID-19 and where full PPE was required, 
3. Confirmed or suspected as having COVID-19 and where full PPE required and AGPs were used.

Working closely with the clinical specialist and using the interview data and RP diagrams the salient factors for inclusion in the DES model were determined. Many tasks associated with CT service provision which were identified during interviews with staff were not included in the model. Such tasks include stock management, continuous professional development, logging of incident forms, training of staff and the vetting of outpatient CT requests. These were not included as to do so would have decreased the reusability and increased the model building complexity; this was not deemed practical and determined to be outside the scope of the model.

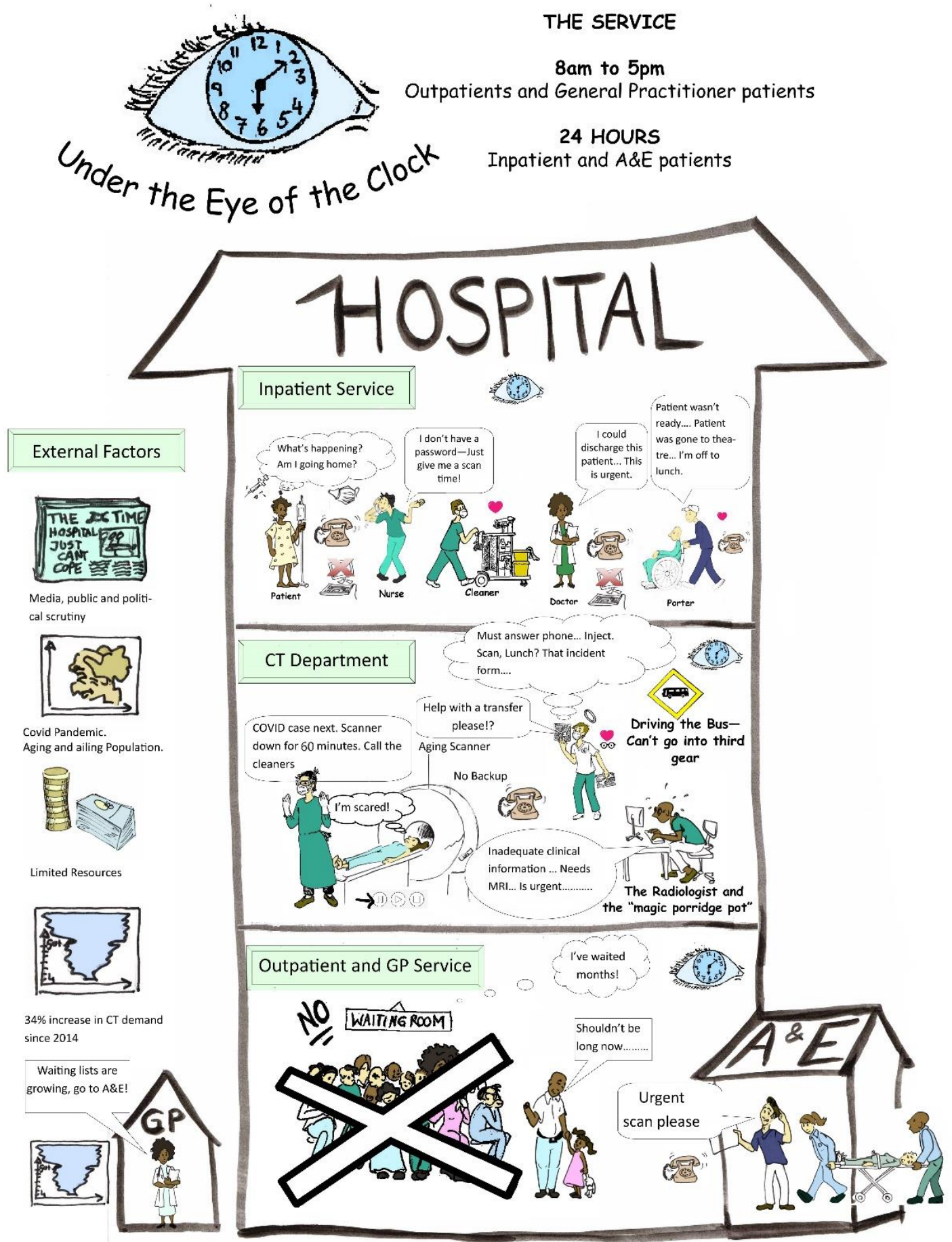

Figure 3 Rich Picture of staff perceptions of service changes post COVID-19 


\subsection{Model Validation}

Verification and validation are executed throughout each phase of the simulation model development. Statistical validation compared model results with historical data using the patient time in radiology from arrival to scan end. This was compared for bias and standard deviation of errors between historical and model outputs. Validation also compared inpatient and outpatient arrival rates and the evolution of the CT waiting list with historical data. For each metric created, individual cases were examined, using logger data and the patient characteristics.

\section{RESULTS}

\subsection{Explanation of the Rich Picture}

In the RP, entitled "under the eye of the clock", a clear definition is made between the inpatient and outpatient sources by locating them on separate floors of the hospital (Figure 3).

Symbols are used to illustrate how the speed of work has been temporarily paused or slowed down. Waiting rooms are no longer crowded as GP and outpatient bookings are limited and patients phoned when the CT scanner is available. Staff shared how prior to COVID-19 everything was considered urgent, but since there is a "more clinical" prioritisation of work. Staff described how in the new COVID-19 environment staff have each other's backs and this is represented by the glasses. A heart indicates how relationships between radiology staff and cleaning staff have improved and staff are now on first name basis. A radiographer in full personal protective equipment (PPE) is seen waiting for the arrival of a COVID-19 patient. The department is closed to all other traffic during this waiting time and will not resume until the scan is complete and the patient has left the cleaned down department. The CT room remains vacant for one hour after a ventilated patient is scanned - again a clock features in the scene. The telephone features five times indicating the constant communications between ward staff, referrers, cleaner, porters and CT staff required to safely schedule and coordinate each CT scan.

\subsection{Model changes post COVID-19}

The workflow for Covid-19 AGP cases was mapped and is presented in Figure 4. The diagram includes the administrative preparatory work as well as the actual scanning of the patient. A questionnaire must be completed with ward staff to ensure that the patient is ready for their scan on arrival. Should the patient require observation additional staff must accompany the patient from the ward as staff wearing full PPE are not permitted in the CT console area. The questionnaire includes questions on their transportation method, details of intravenous (IV) access site, state of dress and the patient's resuscitation status in case of an event while in the department. Scanner and staff utilisation are decreased due to the sixty minutes time delay following AGP cases.

The following changes, identified as part of the RP diagramming exercise, were required to the existing DES model:

- Three additional phone calls pre-CT scan plus completion of COVID-19 questionnaire with staff nurse/referring doctor.

- Three additional phone calls post CT scan to alert ward of patient transit and to alert other departments that radiology is once more accessible for ultrasound and general x-ray patients.

- COVID-19 patients utilising aerosol generating procedures (AGP) such as ventilation, high flow oxygen or suction etc results in 1 hour downtime followed by 15 minutes cleaning and drying time.

- COVID-19 non AGP results in twenty minutes delay plus five mins cleaning and five minutes for drying (provided no delay sourcing cleaning staff).

- Change to OP schedule - OP bookings were decreased from ten examinations per day to four for a period of three months Match to May and again in January 2021.

The model parameters updated post Covid-19 are presented in Table 1. 


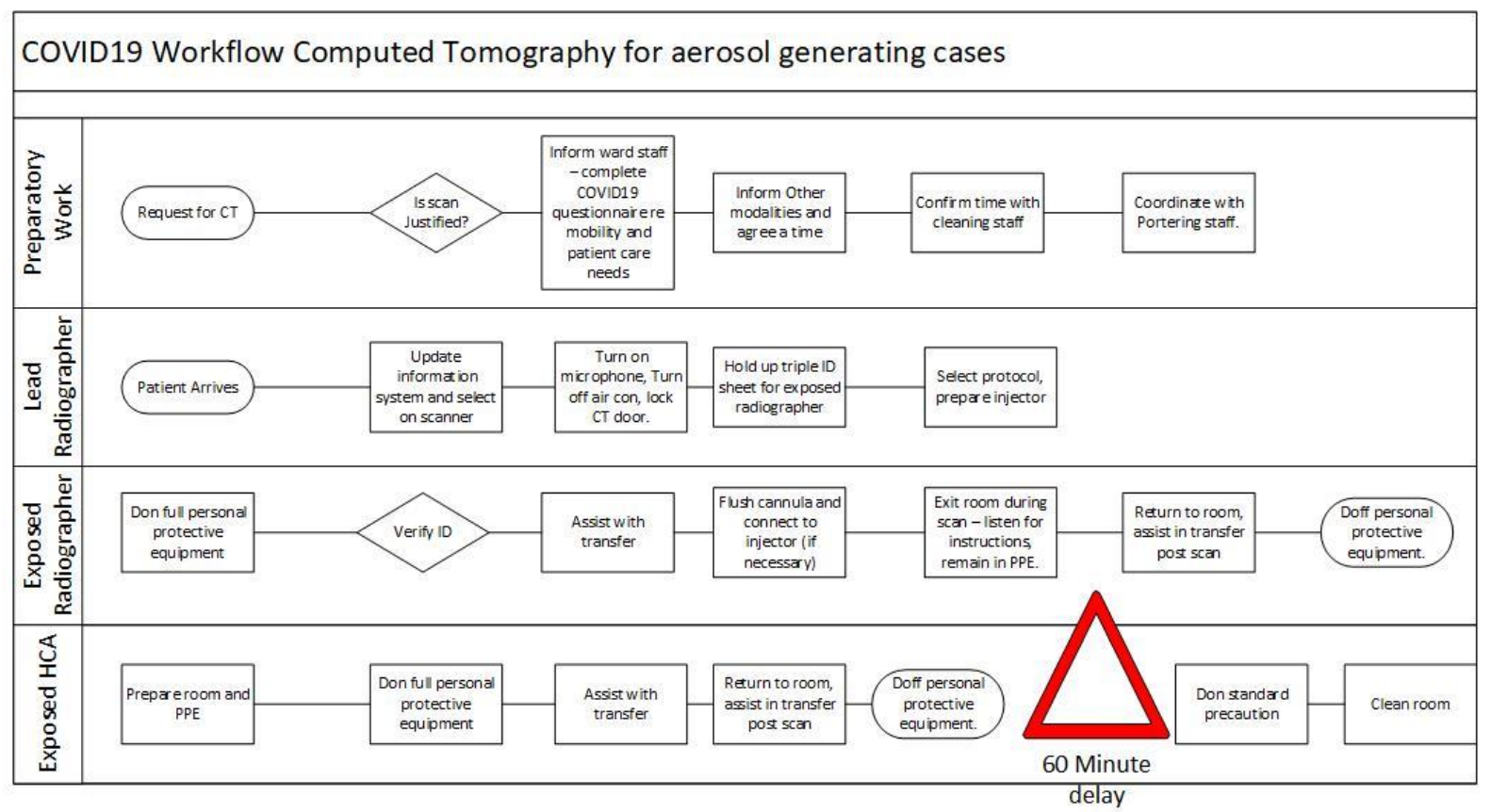

Figure 4 Visio Diagram for CT workflow for COVID-19 positive case

Table 1 Tasks related to infection control

\begin{tabular}{|c|c|c|c|c|}
\hline $\begin{array}{l}\text { Tasks for infectious } \\
\text { patients }\end{array}$ & Staff required & $\begin{array}{c}\text { Time taken } \\
\text { (minutes) }\end{array}$ & $\begin{array}{c}\text { Number } \\
\text { of staff }\end{array}$ & Explanation of task \\
\hline $\begin{array}{l}\text { Standard precautions } \\
\text { clean post scan }\end{array}$ & $\begin{array}{l}\text { Assistant or } \\
\text { Radiographer }\end{array}$ & 7 & 1 & $\begin{array}{l}\text { Cleaning time ( } 2 \\
\text { mins) plus required } \\
\text { drying time ( } 5 \text { mins) }\end{array}$ \\
\hline $\begin{array}{l}\text { Confirmed or } \\
\text { suspected COVID-19 } \\
\text { non AGP clean post } \\
\text { scan }\end{array}$ & $\begin{array}{l}\text { Assistant or } \\
\text { Radiographer cleans } \\
\text { equipment, Hospital } \\
\text { cleaners for floors and } \\
\text { doors }\end{array}$ & 10 & 1 & $\begin{array}{l}\text { Includes cleaning and } \\
\text { drying time }\end{array}$ \\
\hline $\begin{array}{l}\text { Aerosol generating } \\
\text { procedure Covid-19 } \\
\text { clean post scan }\end{array}$ & $\begin{array}{l}\text { Assistant or } \\
\text { Radiographer cleans } \\
\text { equipment, hospital } \\
\text { cleaners touch points }\end{array}$ & 10 & 1 & $\begin{array}{l}\text { NB Room downtime } \\
\text { minutes required } \\
\text { before clean }=60 \\
\text { mins }\end{array}$ \\
\hline $\begin{array}{l}\text { Don/doff standard } \\
\text { precautions }\end{array}$ & Any staff member & 1 & 1 & $\begin{array}{l}\text { Before and after each } \\
\text { scan/activity }\end{array}$ \\
\hline $\begin{array}{l}\text { Don/doff full personal } \\
\text { protective equipment }\end{array}$ & Any staff member & 3 & 1 & $\begin{array}{l}\text { Before and after each } \\
\text { scan/activity }\end{array}$ \\
\hline $\begin{array}{l}\text { Time required to call } \\
\text { and wait for hospital } \\
\text { cleaners }\end{array}$ & Cleaning staff & $(0,15,5)$ & 1 & $\begin{array}{l}\text { triangular delay - } \\
\text { minimum, maximum } \\
\text { and mode time } \\
\text { waiting for cleaning } \\
\text { staff in minutes }\end{array}$ \\
\hline Scan non contrast/oral & Radiographer & 3 & 2 & $\begin{array}{l}\text { Previously } 1 \\
\text { radiographer required }\end{array}$ \\
\hline $\begin{array}{l}\text { Scan involving IV } \\
\text { contrast }\end{array}$ & Radiographer & 7 & 2 & \\
\hline
\end{tabular}


The scenarios identified in partnership with decision makers and the simulation results are presented in Figure 5.

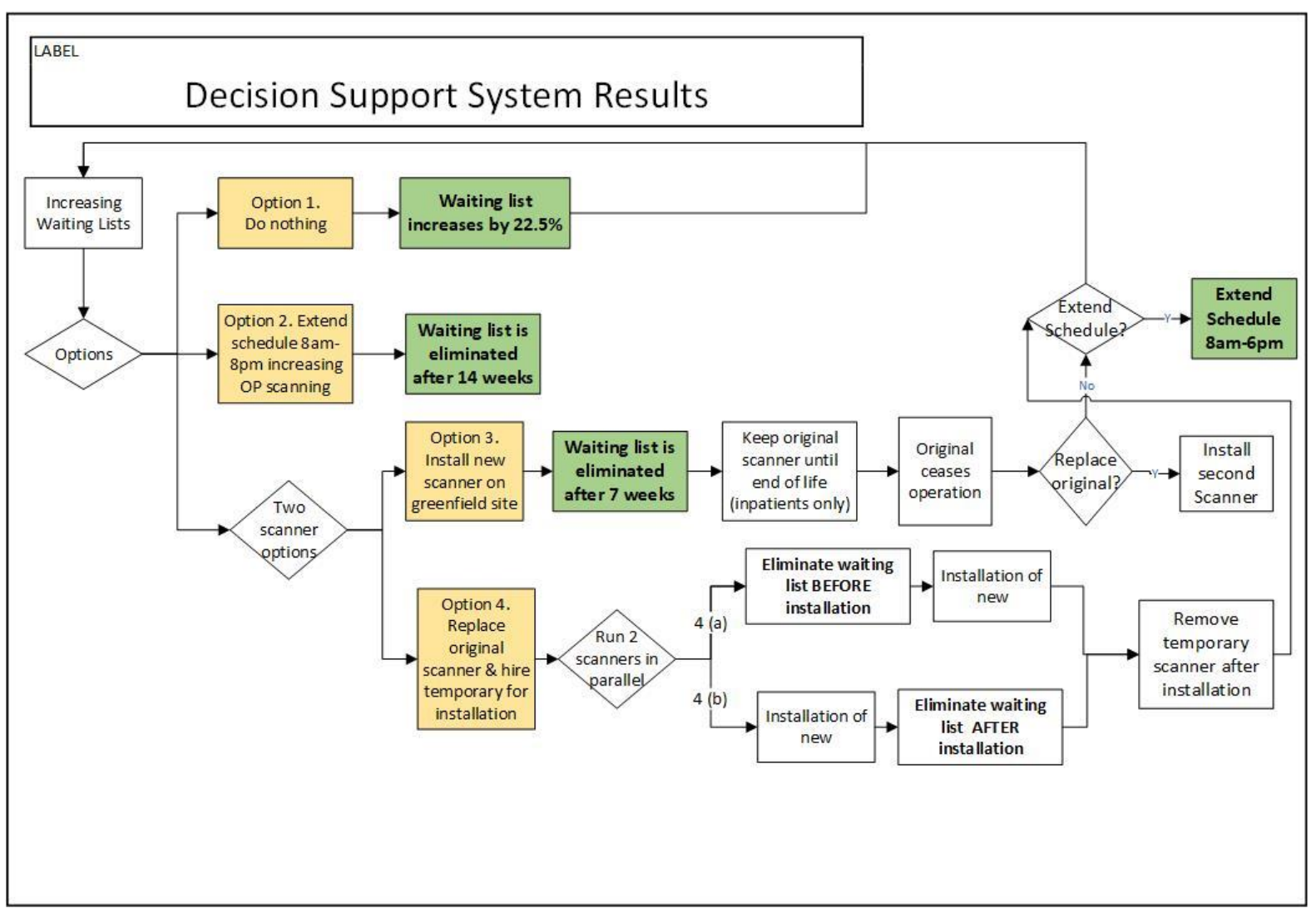

Figure 5 Scenarios identified and simulation model results

The pre COVID-19 consumed staff time (minutes) for exams requiring oral and IV contrast for 653 inpatient and outpatient exams were extracted from the model and are presented in Figure 6a. Post COVID-19, the average consumption of staff time for each examination category, for inpatients, was shown to vary as shown in Figure $6 \mathrm{~b}$.
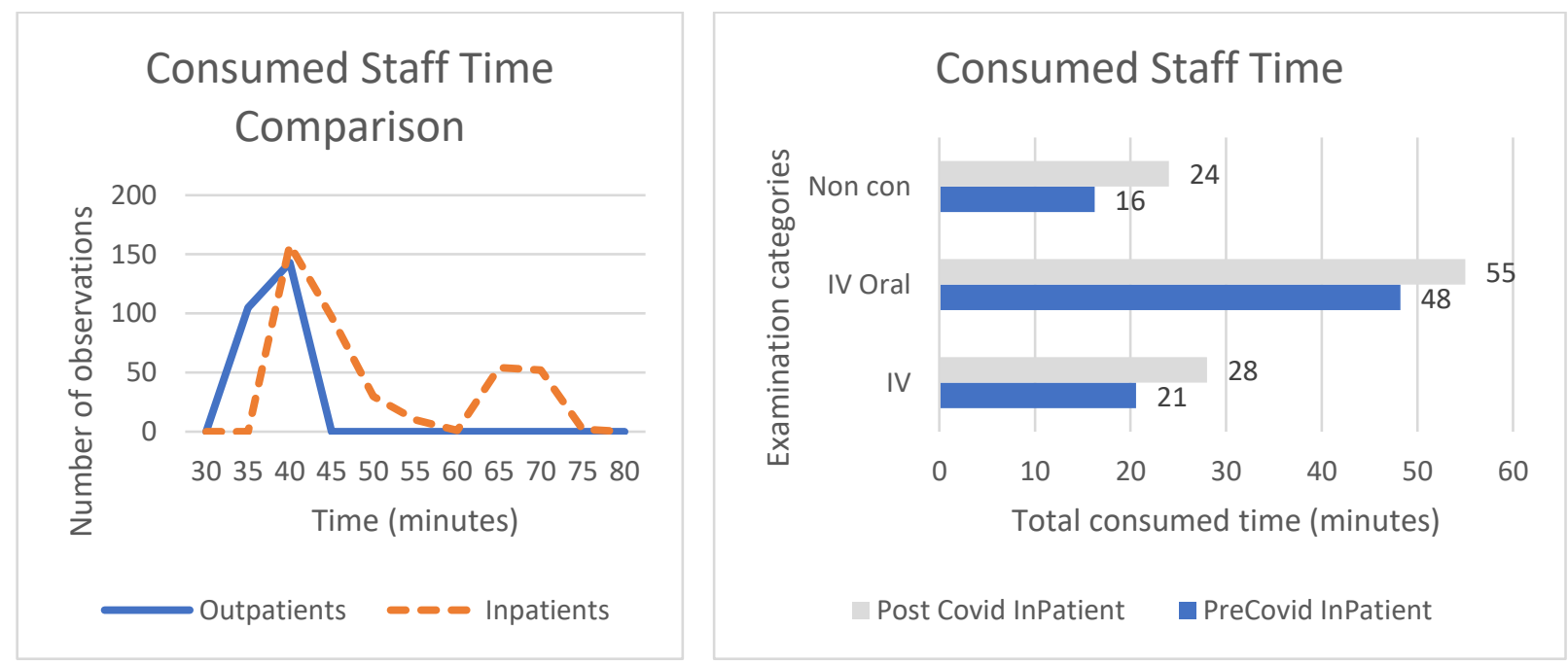

Figure 6a (left) Variation in consumption of staff time by patient cohort pre COVID-19. Figure 6b (right) Effect of COVID-19 on consumption of staff time. 


\subsection{DES model Validation data}

The process was validated by comparing historical and model data for the patient time in system.

Table 2 Validation Results

Mean System Time and Errors for Different Exam Types(minutes)

\begin{tabular}{|l|r|r|}
\hline Exam Categories & $\begin{array}{l}\text { Mean Time in } \\
\text { System }-95 \% \mathrm{Cl}\end{array}$ & Mean Error - $95 \% \mathrm{Cl}$ \\
\hline Overall & $54.4 \pm 1.2$ & $3.36 \pm 0.64$ \\
\hline IV & $33.2 \pm 1.6$ & $-1.81 \pm 1.76$ \\
\hline IVandOral & $118.6 \pm 0.8$ & $8.55 \pm 1.20$ \\
\hline None & $20.5 \pm 0.6$ & $1.76 \pm 0.81$ \\
\hline Oral & $113.0 \pm 3.3$ & $7.30 \pm 4.33$ \\
\hline Procedure & $48.7 \pm 2.7$ & $2.81 \pm 3.01$ \\
\hline
\end{tabular}

\section{DISCUSSION}

The RP (Figure 3) captures the key features of the CT service, staff activities, the process, the environment, the delays, distractions, and some external factors contributing to workload and affecting service delivery. RP diagramming provided a strategic opportunity for meaningful decision-maker involvement allowing a tangible space to discuss and negotiate worthwhile, recommendations for change (Bell et al., 2019). While some argue that SSM is not a decision making tool and rather a post hoc measure to justify the status quo (Bergvall-Kareborn, 2002) it did, in this case study, arrive at a service improvement recommendation (Figure 5) that had not previously been considered. In scenario 3 a new CT scanner is installed on a greenfield site, with the original scanner running in parallel until it ceases operating. Following iterative consultations, it was decided to extend scenario 3 to consider the point in time when the original scanner would cease to operate. The decision, at this point, to replace the original or extend the schedule was included in the DST. The feasibility and desirability of a solution can influence whether it is implemented in practice and as has been reported in past literature the very process of designing and building the simulation model resulted in a greater understanding and appreciation of the behaviour of the service (Monks et al., 2014, 2016; Simon Dodds \& Phillip Debenham, 2016).

Decision makers identified scenario 3 as the most feasible and desirable. Here a new outpatientonly scanner is installed with the original CT scanner allocated to the inpatient and emergency services. This scenario eliminates the waiting list seven weeks post installation and provides redundancy against service downtime while allowing separation of inpatient and outpatient cohorts. Segregation of infectious patient cohorts using designated scanners has been suggested as a measure to help hospitals deal with the COVID-19 pandemic (Huang et al., 2020; Sim et al., 2020). Scenario 3 allows the original scanner to continue to provide a service until it is no longer usable or cost effective to repair, thus maximising its potential. While no benefit was seen in decommissioning earlier than required, it was recognised that the hospital or OP service would experience disruption when the scanner finally ceased operations. The decision support tool includes this future scenario regarding replacement of the original scanner or extension of service hours.

In addition to specific recommendations, the study offered some general insights, in terms of consumed staff hours for inpatient and outpatient cohorts (Figure 6a). Inpatients have long been recognised as "schedule busters" and outpatients as schedule "buffers", and recommendation made to separate these services (Boland, 2008; Murray et al., 2017; Reinus et al., 2000). The additional tasks associated with COVID-19 cases are provided in Figure 4 and Table 1 and were found to result in further work perturbations and increased consumption of staff time (Figure 6a and 6b). Industrial methods such as lean and six sigma advocate the reduction of process variation times and have applications in health (Womack et al., 2007; Young et al., 2004). This work recommends that inpatient and outpatient services be delivered and considered separately.

On a national level this works recommends the establishment of regional diagnostic hubs to provide a dedicated scheduled service for outpatient and GP diagnostic imaging. A scheduled service benefits 
from increased efficiency, reduced variability, and a reduction in infection control related downtime. On the counter side vulnerable inpatients would benefit from not sharing waiting areas and corridors with outpatients and those who accompany them, improving their experience of privacy, dignity and avoidance of degradation (Murray et al., 2017).

When called upon in July 2020 the iterative nature of the framework (Figure 1) proved effective in adapting to the novel problem situation facing the radiology service delivery. This example of model reuse demonstrated how the initial modelling project provided an introduction to the capabilities of operations research and led to its becoming "baked in" as a decision support within the department (Ackoff, 2010). Benefits of the inclusion of decision makers in the research project included:

1. providing them with an opportunity to internalize research knowledge,

2. promotion of trust and consensus building and a more meaningful focus,

3. improvement of relationships,

4. higher likelihood of implementation (Harper \& Pitt, 2004; Monks et al., 2016; Ross et al., 2003).

The radiology manager commented that while radiographers "naturally understood patient and process complexity, the model was useful when communicating with higher levels of decision makers".

\subsection{Limitations and Future Work}

Patient care remains largely unquantified and further research is recommended into the use of operational research methods for modelling patient care activities. It is recommended that future models allocate time for patient care or reference be made to it in model assumptions. The quality of reassurance, obtaining of informed consent, exam explanations and preparedness of the patient for diagnostic imaging can be eroded where additional workload is absorbed and time per exam reduced. As departments become busier we risk a "production-line" mentality that impedes compassionate care (Sinclair et al., 2016).

Following on from this work further application of the framework has been suggested for other imaging modalities in the department such as general $\mathrm{x}$-ray and ultrasound.

\section{CONCLUSION}

The original objective of this work was to understand how the CT service has changed due to COVID19 and to describe the repurposing of an existing DES model. Subjective and objective aspects of the impact of COVID-19 in terms of staff perception of their service, the workflow and the consumption of staff time have been quantified and graphically depicted. The creation of the RP provided an opportunity for staff to reflect on the current environment and service they provide and should be interesting to refer to in future times. COVID-19 has led to a decreased outpatient service and scanner availability, as well as increased workflow complexity and communications. The full extent of the impact of COVID-19 on the GP and outpatient populations is unknown. An approach using DES and SSM could prove successful to examine how best to manage future demand. This work recommends that inpatient and outpatient services be delivered separately and that, on a national level, regional diagnostic hubs be established to provide dedicated services for outpatient and GP diagnostic imaging.

\section{ACKNOWLEDGMENTS}

We would like to acknowledge the artistic contribution provided by Nora Zölzer-Bryce who produced the Rich Picture diagram. Nora is an artist and nurse with the Irish Wheelchair Association. Thanks, is also due to Caroline Hanrahan, Radiology Manager, Dr Parsons, Clinical Director and all the staff in Portiuncula University Hospital, clinical, clerical, and household for their participation.

\section{REFERENCES}

Ackoff, R. L. (2010). Systems thinking for curious managers. Triarchy Press. 
Adam, E. J. (2006). Changes in the computed tomography patient population. European Radiology, Supplement, 16(SUPPL. 4), 38-42. https://doi.org/10.1007/s10406-006-0186-1

Bell, S., Berg, T., \& Morse, S. (2019). Towards an Understanding of Rich Picture Interpretation. Systemic Practice and Action Research (2019), 32, 601-614. https://doi.org/10.1007/s11213-0189476-5

Bergvall-Kareborn, B. (2002). Enriching the model-building phase of soft systems methodology. (Research Paper). Systems Research and Behavioral Science, 19(1), 27-49. https://go-galecom.libgate.library.nuigalway.ie/ps/i.do? $\mathrm{p}=\mathrm{AONE} \& \mathrm{sw}=\mathrm{w} \& \mathrm{issn}=10927026 \& \mathrm{v}=2.1 \& \mathrm{it}=\mathrm{r} \& \mathrm{id}=\mathrm{G}$ ALE\%7CA83281263\&sid=googleScholar\&linkaccess=fulltext

Boland, G. W. L. (2008). Enhancing CT productivity: Strategies for increasing capacity. American Journal of Roentgenology, 191(1), 3-10. https://doi.org/10.2214/AJR.07.3208

Booker, M. T., O'Connell, R. J., Desai, B., \& Duddalwar, V. A. (2016). Quality Improvement with Discrete Event Simulation: A Primer for Radiologists. Journal of the American College of Radiology, 13(4), 417-423. https://doi.org/10.1016/j.jacr.2015.11.028

Central Statistics Office. (2015). Regional Population Projections 2016 - 2031 - CSO - Central Statistics http://www.cso.ie/en/releasesandpublications/er/rpp/regionalpopulationprojections2016-2031/

Conlon, M., \& Molloy, O. (2019). Knowledge management in healthcare: Information requirements when creating a decision support tool in radiology. IC3K 2019 - Proceedings of the 11th International Joint Conference on Knowledge Discovery, Knowledge Engineering and Knowledge Management, 3(Ic3k), 317-324. https://doi.org/10.5220/0008352703170324

Crowe, S., Brown, K., Tregay, J., Wray, J., Knowles, R., Ridout, D. A., Bull, C., \& Utley, M. (2017). Combining qualitative and quantitative operational research methods to inform quality improvement in pathways that span multiple settings. BMJ Quality \& Safety, 26(8), 641-652. https://doi.org/10.1136/bmjqs-2016-005636

Currie, C. S., Fowler, J. W., Kotiadis, K., Monks, T., Stephan Onggo, B., Robertson, D. A., Tako, A. A., \& Currie, S. (2020). How simulation modelling can help reduce the impact of COVID-19. https://doi.org/10.1080/17477778.2020.1751570

Gunal, M. M. (2012). A guide for building hospital simulation models. Health Systems, 1(1), 17-25. https://doi.org/10.1057/hs.2012.8

Harper, P. R., \& Pitt, M. a. (2004). On the challenges of healthcare modelling and a proposed project life cycle for successful implementation. 55(6), 657-661. https://doi.org/10.1057/palgrave.jors.2601719

HSE. (2020). Guidance on COVID-19 (Vol. 2).

Huang, Z., Zhao, S., Li, Z., Chen, W., Zhao, L., Deng, L., \& Song, B. (2020). The Battle Against Coronavirus Disease 2019 (COVID-19): Emergency Management and Infection Control in a Radiology Department. Journal of the American College of Radiology, 17(6), 710-716. https://doi.org/10.1016/j.jacr.2020.03.011

Monks, T., Robinson, S., \& Kotiadis, K. (2014). Learning from discrete-event simulation: Exploring the high involvement hypothesis. https://doi.org/10.1016/j.ejor.2013.10.003

Monks, T., Robinson, S., \& Kotiadis, K. (2016). Can involving clients in simulation studies help them solve their future problems? A transfer of learning experiment. European Journal of Operational Research, 249(3), 919-930. https://doi.org/10.1016/j.ejor.2015.08.037

Mossa-Basha, M., Meltzer, C. C., Kim, D. C., Tuite, M. J., Kolli, K. P., \& Tan, B. S. (2020). Radiology Department Preparedness for COVID-19: Radiology Scientific Expert Panel. Radiology, 200988. https://doi.org/10.1148/radiol.2020200988

Murray, T. E., Halligan, J. J., \& Lee, M. J. (2017). Inefficiency, dignity and patient experience: Is it time for separate outpatient diagnostics? British Journal of Radiology, 90(1080), 4-6. https://doi.org/10.1259/bjr.20170574

Oh, H.-C., Toh, H.-G., \& Giap Cheong, E. S. (2011). Realization of Process Improvement at a Diagnostic Radiology Department with Aid of Simulation Modeling. Journal For Healthcare Quality, 33(6), 40-47. https://doi.org/10.1111/j.1945-1474.2011.00133.x

Orsi, M. A., Oliva, A. G., \& Cellina, M. (2020). Radiology Department Preparedness for COVID-19: Facing an Unexpected Outbreak of the Disease. Radiology, 201214. 
https://doi.org/10.1148/radiol.2020201214

Rachuba, S., Knapp, K., Ashton, L., \& Pitt, M. (2018). Streamlining pathways for minor injuries in emergency departments through radiographer-led discharge. Operations Research for Health Care, 19, 44-56. https://doi.org/10.1016/j.orhc.2018.03.001

Reinus, W. R., Enyan, a, Flanagan, P., Pim, B., Sallee, D. S., \& Segrist, J. (2000). A proposed scheduling model to improve use of computed tomography facilities. Journal of Medical Systems, 24(2), 61-76. http://www.ncbi.nlm.nih.gov/pubmed/10895421

Ross, S., Lavis, J., Rodriguez, C., Woodside, J., \& Denis, J. L. (2003). Partnership experiences: Involving decision-makers in the research process. Journal of Health Services Research and Policy, 8(SUPPL. 2), 26-34. https://doi.org/10.1258/135581903322405144

Sim, W. Y., Chen, R. C., Aw, L. P., Abu Bakar, R., Tan, C. C., Heng, A. L., \& Ooi, C. C. (2020). How to safely and sustainably reorganise a large general radiography service facing the COVID-19 pandemic. Radiography, https://doi.org/10.1016/j.radi.2020.05.001

Simon Dodds, A., \& Phillip Debenham, S. (2016). Learning Anti-Chaos Design in Emergency Flow. Journal of Improvement Science, 32, 1-14. http://www.journalofimprovementscience.net

Sinclair, S., Norris, J. M., McConnell, S. J., Chochinov, H. M., Hack, T. F., Hagen, N. A., McClement, S., \& Bouchal, S. R. (2016). Compassion: a scoping review of the healthcare literature. BMC Palliative Care, 15(1), 6. https://doi.org/10.1186/s12904-016-0080-0

Sterman, J. D. (2001). System Dynamics Modeling: Tools for Learning in a Complex World. California Management Review, 43(4), 8-25. https://doi.org/10.1111/j.1526-4637.2011.01127.x

The Royal College of Radiologists. (2020a). Clinical Radiology UK Workforce Census 2019 Report. Clinical Radiology, April. http://www.rcr.ac.uk/publications.aspx?PageID=310\&PublicationID=359

The Royal College of Radiologists. (2020b). Clinical Radiology UK Workforce Census 2019 Report. Clinical Radiology, April.

Van Lent, W. A. M., Deetman, J. W., Teertstra, H. J., Muller, S. H., Hans, E. W., \& Van Harten, W. H. (2012). Reducing the throughput time of the diagnostic track involving CT scanning with computer simulation. European Journal of Radiology, 81, 3131-3140. https://doi.org/10.1016/j.ejrad.2012.03.012

Womack, James, Jones, Daniel, Roos, D. (2007). The machine that changed the world. Simon \& Schuster.

Young, T., Brailsford, S., Connell, C., Davies, R., Harper, P., \& Klein, J. H. (2004). Using industrial processes to improve patient care. BMJ (Clinical Research Ed.), 328(7432), 162-164. https://doi.org/10.1136/bmj.328.7432.162

Zanardo, M., Martini, C., Monti, C. B., Cattaneo, F., Ciaralli, C., Cornacchione, P., \& Durante, S. (2020). Management of patients with suspected or confirmed COVID-19, in the radiology department. Radiography. https://doi.org/10.1016/j.radi.2020.04.010

\section{AUTHOR BIOGRAPHIES}

MARY CONLON received a BSc (Hons) Radiography and Diagnostic Imaging from University of Wales, Bangor in 1998 and MSc Radiography from University College Dublin in 2008. She is currently a Senior radiographer in Ireland's Health Service Executive and PhD student in the National University of Ireland, Galway.

OWEN MOLLOY is lecturer and PhD supervisor at the National University of Ireland, Galway. He holds Doctoral (Industrial Engineering), Masters (Electronic Engineering) and Bachelors (Electronic Engineering) degrees from the National University of Ireland.

AVRIL HANLY received a BSc (Hons) Radiography and Diagnostic Imaging from University of Hertfordshire, and post graduate qualification in CT. She is the CT Clinical Specialist in Portiuncula University Hospital, Health Service Executive, with a special interest in continuous process improvement and applications of Lean in Healthcare. 